\title{
Environmental Science
}

\section{Evaluation of $\mathrm{Pt}$, $\mathrm{Ni}$, and $\mathrm{Ni}-\mathrm{Mo}$ electrocatalysts for hydrogen evolution on crystalline Si electrodes $\dagger$}

\author{
James R. McKone, Emily L. Warren, Matthew J. Bierman, Shannon W. Boettcher, $\$$ Bruce S. Brunschwig, \\ Nathan S. Lewis* and Harry B. Gray*
}

Received 19th April 2011, Accepted 22nd June 2011

DOI: 10.1039/c1ee01488a

\begin{abstract}
The dark electrocatalytic and light photocathodic hydrogen evolution properties of Ni, Ni-Mo alloys, and $\mathrm{Pt}$ on Si electrodes have been measured, to assess the viability of earth-abundant electrocatalysts for integrated, semiconductor coupled fuel formation. In the dark, the activities of these catalysts deposited on degenerately doped $\mathrm{p}^{+}-\mathrm{Si}$ electrodes increased in the order $\mathrm{Ni}<\mathrm{Ni}-\mathrm{Mo} \leq \mathrm{Pt}$. Ni-Mo deposited on degenerately doped $\mathrm{Si}$ microwires exhibited activity that was very similar to that of $\mathrm{Pt}$ deposited by metal evaporation on planar Si electrodes. Under $100 \mathrm{~mW} \mathrm{~cm}{ }^{-2}$ of Air Mass 1.5 solar simulation, the energy conversion efficiencies of p-type Si/catalyst photoelectrodes ranged from $0.2-1 \%$, and increased in the order $\mathrm{Ni} \approx \mathrm{Ni}-\mathrm{Mo}<\mathrm{Pt}$, due to somewhat lower photovoltages and photocurrents for $\mathrm{p}-\mathrm{Si} / \mathrm{Ni}-\mathrm{Mo}$ relative to $\mathrm{p}-\mathrm{Si} / \mathrm{Ni}$ and $\mathrm{p}-\mathrm{Si} / \mathrm{Pt}$ photoelectrodes. Deposition of the catalysts onto microwire arrays resulted in higher apparent catalytic activities and similar photoelectrode efficiencies than were observed on planar p-Si photocathodes, despite lower light absorption by $\mathrm{p}-\mathrm{Si}$ in the microwire structures.
\end{abstract}

\section{Introduction}

An approach to artificial photosynthesis involves the use of semiconductors to capture and convert sunlight into chargeseparated electrons and holes. The separated charge carriers would then be coupled to suitable electrocatalysts to facilitate multi-electron transfer processes that effect, at low overpotentials, the oxidation of water to $\mathrm{O}_{2}(\mathrm{~g})$ and the reduction of water to $\mathrm{H}_{2}(\mathrm{~g}){ }^{1,2}$ Semiconductor photocathodes have shown high efficiency for production of $\mathrm{H}_{2}(\mathrm{~g})$ from $\mathrm{H}_{2} \mathrm{O}$, with nearly unity internal quantum yields throughout the visible region of

Beckman Institute and Kavli Nanoscience Institute, Division of Chemistry and Chemical Engineering, California Institute of Technology, 1200 East California Blvd, Pasadena, California, 91125, USA.E-mail: nslewis@, caltech.edu; hbgray@caltech.edu

$\uparrow$ Electronic supplementary information (ESI) available. See DOI: $10.1039 / \mathrm{clee} 01488 \mathrm{a}$

\$ Current address: Department of Chemistry, University of Oregon, Eugene OR. the solar spectrum. ${ }^{3}$ For example, $\mathrm{p}$-InP/Rh photocathodes have yielded $11 \%$ thermodynamically based energy conversion efficiencies of $\mathrm{HCl}(\mathrm{aq})$ to $\mathrm{H}_{2}(\mathrm{~g}){ }^{4}$ Additionally, p-type Si photocathodes with an overlayer of Pt nanoparticles have been shown to produce $>5 \%$ thermodynamically based conversion efficiency of protons to $\mathrm{H}_{2}(\mathrm{~g})$ under low-level monochromatic $(632 \mathrm{~nm})$ light in mildly acidic aqueous solution. ${ }^{5}$ Several devices that have incorporated multi-junction semiconductor photoelectrodes have effected the overall solar-driven splitting of water to $\mathrm{H}_{2}(\mathrm{~g})$ and $\mathrm{O}_{2}(\mathrm{~g})$ with $>5 \%$ efficiency. ${ }^{6,7}$

A globally scalable system for production of $\mathrm{H}_{2}(\mathrm{~g})$ from sunlight and $\mathrm{H}_{2} \mathrm{O}$ will require light absorbers and electrocatalysts that are made from earth-abundant materials. In this respect, photocathodes formed from $\mathrm{Si}$ microwire arrays are attractive. The microwire array geometry orthogonalizes the directions of light absorption and charge-carrier collection, thereby facilitating the use of materials that have relatively low minoritycarrier collection lengths. ${ }^{8}$ Such materials, in turn, can be grown

\section{Broader context}

The development of carbon-neutral energy supplies is a critical goal for the 21 st century. Solar energy is a massive resource, but to enable its use upon demand, storage methods, especially in the form of chemical fuels, are needed. Catalysts are required to convert with low energy loss the uncorrelated electron-hole pairs produced by captured sunlight into processes that make and break chemical bonds. Most such catalysts, however, contain rare and expensive second- or third-row transition metals. In this work, we have demonstrated the advantageous use of structured, high internal surface area microwire array semiconducting electrodes to obtain performance from abundant metal catalysts such as $\mathrm{Ni}$ or $\mathrm{Ni}-\mathrm{Mo}$ that is sufficient to convert water into $\mathrm{H}_{2}(\mathrm{~g})$ with small energy loss at a rate comparable to the unconcentrated solar flux. 
using high growth rate methods such as the vapor-liquid-solid growth technique. ${ }^{9,10}$ Exploitation of the orthogonalization approach has to date yielded $\mathrm{Si}$ microwire array-based radial $\mathrm{n}^{+}-\mathrm{p}$ junction photovoltaic devices that, while only absorbing $60 \%$ of the light, have resulted in $7 \%$ solar energy conversion efficiencies under simulated Air Mass (AM) 1.5 illumination conditions. ${ }^{11}$ Radial $\mathrm{n}^{+}$-p junction Si microwire array photocathodes that have been decorated with islands of $\mathrm{Pt}$ as an electrocatalyst have yielded, with only $\sim 50 \%$ light absorption, $>5 \%$ thermodynamically based energy conversion efficiencies for the production of $\mathrm{H}_{2}(\mathrm{~g})$ from $0.5 \mathrm{M} \mathrm{H}_{2} \mathrm{SO}_{4}(\mathrm{aq})$ under simulated AM1.5 illumination. ${ }^{12}$ A goal is therefore to use earth-abundant electrocatalysts to achieve performance for $\mathrm{H}_{2}(\mathrm{~g})$ evolution that is comparable to that obtainable using $\mathrm{Pt}$ or $\mathrm{Pd}$ as electrocatalysts.

The use of microwire arrays, or other electrodes that have a high ratio of their internal surface area to their projected, geometric area (i.e. a large roughness factor, $\gamma$ ) relaxes the constraints on catalyst activity needed to produce, at low overpotentials, fuels from sunlight. In an optimally operating tandem light absorbing structure under 1 Sun of AM 1.5 illumination, the solar photon flux will produce a charge-carrier flux of $\sim 10$ $20 \mathrm{~mA} \mathrm{~cm}^{-2}$ to a planar electrode surface. This flux dictates the electrocatalytic activity necessary under unconcentrated AM1.5 sunlight for an efficient sunlight-driven water splitting system. Materials that have high $\gamma$ values should relax this constraint on the needed catalytic activity, because the photogenerated chargecarrier flux can be distributed over a high internal surface area (Fig. 1). Hence for photoelectrodes with a high $\gamma$ value, a lower inherent electrocatalytic activity is required to support the photogenerated charge-carrier flux relative to that needed to produce efficient planar photoelectrode. Stated differently, electrodes with high $\gamma$ values provide an increased number of catalytic centers, and therefore lower the turnover frequency required of each catalyst unit.

The goal of this work is to identify earth abundant materials that could provide sufficient electrocatalytic performance to

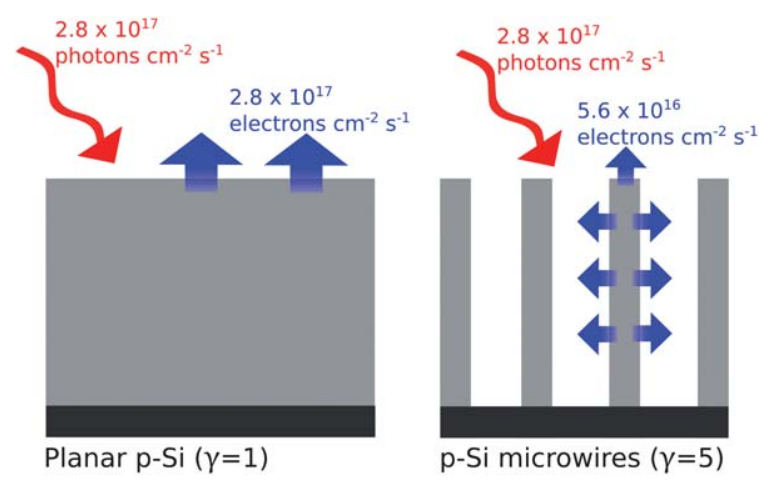

Fig. 1 Relationship between the incident photon flux and outgoing electron flux in a conventional crystalline $\mathrm{Si}$ absorber (left), and a crystalline Si microwire array (right) under AM1.5 illumination, assuming unity absorption above the Si bandgap and unity quantum yield for charge carrier collection. The microwire array produces a smaller electron flux per absorber surface area, even for the same incident photon flux, due to the roughness factor of $\gamma=5$ that results from its microstructured geometry. support the low overpotential production of $\mathrm{H}_{2}(\mathrm{~g})$ on $\mathrm{Si}$ photocathode surfaces under solar illumination. One approach is to enhance the low electrocatalytic activity of abundant materials by exploiting the large $\gamma$ values obtainable for Si microwire array structures and related photoelectrode morphologies. $\mathrm{Ni}$ and $\mathrm{Ni}-$ Mo are known electrocatalysts for $\mathrm{H}_{2}(\mathrm{~g})$ production, ${ }^{13-19}$ and in smooth forms $(\gamma \approx 1)$ have exhibited exchange current densities between $10^{-6}$ and $10^{-4} \mathrm{~A} \mathrm{~cm}^{-2}$ in acidic electrolyte, compared to $10^{-3} \mathrm{~A} \mathrm{~cm}^{-2}$ for $\mathrm{Pt}^{14,19}$ Although $\mathrm{Ni}$ or $\mathrm{Ni}-\mathrm{Mo}$ would provide inferior performance at high current densities compared to $\mathrm{Pt}$, e.g. in proton-exchange membrane (PEM) based electrolyzers, which must minimize the area-related capital expenses associated with the membrane-electrode assembly and the balance of systems in such devices, such electrocatalysts might be viable alternatives to $\mathrm{Pt}$, when deposited onto $\mathrm{Si}$ microwire array photocathode surfaces.

Accordingly, we have investigated the behavior of $\mathrm{Ni}$ and $\mathrm{Ni}-$ Mo alloy electrodeposited from weakly acidic solutions onto planar and microwire array Si substrates, respectively, of either degenerate $\left(\mathrm{p}^{+}\right)$or $\mathrm{p}$-type doping. The electrochemical and photoelectrochemical hydrogen evolution reaction (HER) activities of these composite electrodes have been compared to each other as well as to that of two types of Si/Pt electrodes. The photoelectrode behavior of such systems has been correlated with the catalyst composition and morphology, and with the known characteristics of $\mathrm{p}$-Si photocathodes and Si microwire arrays, to assess the viability of this class of non-noble catalysts for use in photoelectrochemical $\mathrm{H}_{2}(\mathrm{~g})$ production systems.

\section{Experimental}

\section{A. Fabrication of electrodes}

Si wafers of (100) orientation and p-type doping with resistivities, $\rho$, of $\sim 0.7 \Omega \mathrm{cm}$ (p-Si), were obtained from Silicon Inc. Degenerately doped p-type, (111)-oriented $\mathrm{Si}$ wafers with $\rho<0.001 \Omega \mathrm{cm}\left(\mathrm{p}^{+}-\mathrm{Si}\right)$ were obtained from Silicon Quest International. Si microwire arrays were grown on $\mathrm{p}^{+}-\mathrm{Si}$ substrates by an atmospheric pressure chemical vapor deposition (CVD) technique that used $\mathrm{Cu}$ as a vapor-liquid-solid (VLS) growth catalyst. ${ }^{9}$ The hexagonal wire pattern was determined by the pattern of the $\mathrm{Cu}$, which was defined by evaporation and lift-off of $\mathrm{Cu}$ into lithographically etched holes in $\mathrm{a} \mathrm{SiO}_{2}$ buffer layer on the $\mathrm{Si}$ substrate. For wire growth, $\mathrm{SiCl}_{4}(\mathrm{~g})$ was the Si source and $\mathrm{BCl}_{3}(\mathrm{~g})$ was the boron source, resulting in p-type doping of the crystalline $\mathrm{Si}$ microwires. After growth, the microwire arrays were etched to remove the $\mathrm{Cu}$ growth catalyst from the wire surfaces (see ESI $\dagger$ ).

Planar $\mathrm{p}^{+}-\mathrm{Si}$ electrodes, and all Si microwire array electrodes, were fabricated by a multistep procedure in which the wafer/ array was first scribed and cut into pieces that were $\sim 5 \mathrm{~mm}$ on a side. An ohmic back contact was then formed by use of a diamond scribe to scratch a Ga/In eutectic mixture (Aldrich) onto the unpolished back sides of the pieces. The pieces were then affixed to tinned copper wire using silver paint (SPI, Inc.), and allowed to dry overnight. The resulting electrode assembly was sealed onto a glass capillary using a 2-part epoxy (Hysol 1C; chosen for chemical stability). The final electrode area was defined using Hysol 9460 epoxy (chosen for dark color and high 
viscosity before curing). Planar p-Si electrodes were fabricated according to the same process, except that the back, ohmic contact was provided by sputter-deposition of $\sim 500 \mathrm{~nm}$ of $\mathrm{Al}$, followed by heating the sample for $10 \mathrm{~min}$ at $450{ }^{\circ} \mathrm{C}$ under vacuum. Immediately prior to use, all of the $\mathrm{Si}$ electrodes were etched in aqueous $\mathrm{NH}_{4} \mathrm{~F} / \mathrm{HF}$ (buffered $\mathrm{HF}$, Transene) until the surfaces were hydrophobic, indicating the removal of surface $\mathrm{Si}$ oxides and the formation of surface Si hydrides.

\section{B. Deposition of electrocatalysts}

1. Deposition of Ni or Ni-Mo. Ni was electrodeposited from a sulfamate solution that consisted of $325 \mathrm{~g} \mathrm{~L}^{-1} \mathrm{Ni}$ (II) sulfamate and $30 \mathrm{~g} \mathrm{~L}^{-1} \mathrm{H}_{3} \mathrm{BO}_{3}$, with the $\mathrm{pH}$ adjusted to $\sim 4.0$ using $\mathrm{KOH} .{ }^{20}$ For deposition of $\mathrm{Ni}-\mathrm{Mo}, 5 \mathrm{~g} \mathrm{~L}^{-1} \mathrm{Na}_{2} \mathrm{MoO}_{4}$ were added to the above solution before final adjustment of the $\mathrm{pH}$.

Electrodeposition was carried out either galvanostatically or potentiostatically, using a Gamry Reference 600 potentiostat/ galvanostat. Depositions were performed in air, in a onecompartment cell, using a large area $\mathrm{Ni}$ counter electrode and a $\mathrm{Ag} / \mathrm{AgCl}\left(1 \mathrm{M} \mathrm{KCl}, E^{\circ \prime}=+0.222 \mathrm{~V}\right.$ vs. the normal hydrogen electrode, NHE) reference electrode.

$\mathrm{Ni}$ was deposited for $0.5-5 \mathrm{~s}$ onto planar Si electrodes by application of a bias sufficient to produce a cathodic current density of $20 \mathrm{~mA} \mathrm{~cm}^{-2}$, resulting in passage of $10-100 \mathrm{mC} \mathrm{cm}^{-2}$ of cathodic charge density. Ni-Mo deposition onto planar $\mathrm{Si}$ electrodes was performed for 5-180 s at a cathodic current density of $20 \mathrm{~mA} \mathrm{~cm}^{-2}$, producing $100-3600 \mathrm{mC} \mathrm{cm}^{-2}$ of cathodic charge density. Electrocatalyst deposition on Si microwire array electrodes was performed galvanostatically at $50 \mathrm{~mA} \mathrm{~cm}$ of cathodic current density, or was performed potentiostatically at a potential that produced $\sim 20 \mathrm{~mA} \mathrm{~cm}{ }^{-2}$ of cathodic current density on the corresponding planar Si electrode surface. The range of total deposition times tested for $\mathrm{Si}$ microwire array electrodes was somewhat longer than for planar Si electrodes.

All $\mathrm{p}^{+}-\mathrm{Si}$ electrodes were sufficiently conductive that they behaved like metals in the plating solution. In contrast, the $\mathrm{p}-\mathrm{Si}$ photoelectrodes exhibited carrier depletion in the plating solution, which generated a barrier to cathodic current flow in the dark. These electrodes were therefore illuminated using an ELHtype tungsten-halogen light source that was placed immediately adjacent to the cell that contained the plating solution. The $\mathrm{Si}$ microwire electrodes were tilted at a slight angle relative to the incident light propogation vector, thereby providing sufficient absorbed photon flux to effect facile transfer of photogenerated charge carriers across the interface and thus enable photodeposition of the electrocatalyst.

The conditions and time intervals for electrocatalyst deposition produced a range of catalyst loadings on the Si surface, as observed by scanning electron microscopy (SEM). In some cases, the electrocatalysts were deposited in several stages, with HER testing between each stage, to observe increases or decreases in the catalytic activity as a function of increases in catalyst loading. The non-noble catalyst coatings were stable over the several hour timescale of photoelectrochemical measurements.

2. Deposition of Pt. Pt was deposited onto planar or microwire $\mathrm{Si}$ electrodes by electroless deposition or by electron beam (e-beam) evaporation. The electroless deposition of $\mathrm{Pt}$ was performed by placing a drop of $1 \mathrm{mM} \mathrm{K}_{2} \mathrm{PtCl}_{6}(\mathrm{aq})$ in $0.5 \mathrm{M} \mathrm{HF}$ (aq) on the electrode surface for $2 \mathrm{~min}$, followed by a thorough rinse with $>18 \mathrm{M} \Omega$ resistivity $\mathrm{H}_{2} \mathrm{O}$. The HER performance of the electrode was then evaluated, and the process was repeated until the HER activity, as measured by the cathodic current density passed at a given potential (vide infra), reached a plateau or started to decrease. Generally the highest catalytic activity was observed after a total time of 4-6 min of plating. E-beam evaporation of $\mathrm{Pt}$ was performed under a vacuum of $<10^{-5}$ torr in a Denton Explorer evaporator system. Approximately $1 \mathrm{~nm}$ of $\mathrm{Pt}$ was evaporated onto a completely assembled electrode, at a deposition rate of $0.1-1 \AA \mathrm{s}^{-1}$.

\section{Characterization of deposited electrocatalysts}

Structural characterization of the various electrocatalyst deposits on Si electrodes was performed using a Zeiss model 1550 fieldeffect scanning electron microscope. To prepare samples for characterization by SEM, the glass tube in which the sample had been mounted was scribed and broken, to expose a length of bare $\mathrm{Cu}$ wire. The sample was then fixed to the sample stage, and to minimize charging effects, the bare $\mathrm{Cu}$ wire was electrically grounded to the stage. Electron micrographs were collected promptly after the current-potential behavior of the electrodes had been determined with regard to $\mathrm{H}_{2}(\mathrm{~g})$ evolution.

Further structural characterization was performed using an FEI TF30UT transmission electron microscope (TEM) that was equipped with a HAADF STEM detector, an Oxford energydispersive X-ray detector, and a high-resolution CCD camera. For TEM analysis, a layer of catalyst was deposited onto a $\mathrm{Si}$ electrode and was subsequently scraped off with a stainless steel razor blade. The resulting powder was suspended in isopropanol and then drop cast onto a lacey carbon/Cu grid. Compositional and crystal phase data were collected using energy-dispersive X-ray spectroscopy (EDS) and electron diffraction, respectively. The SEM and TEM images were subjected to a minimum of post-processing, being limited to normalization of the whitebalance to a level that produced optimal contrast in the images.

$\mathrm{X}$-ray photoelectron spectroscopic (XPS) analysis was carried out using a Kratos Ultra DLD instrument that was equipped with a magnetic immersion lens with a spherical mirror and concentric hemispherical analyzers. All XP spectra were fit using a software package that was written in-house and minimized the $\chi^{2}$ fitting error with the Levenberg-Marquardt algorithm. Spectra were fit with Gaussian-Lorentzian line shapes above a Shirley background with no asymmetric profiles.

\section{Electrochemical measurements}

The activities of the various catalysts and the performance of photoelectrodes were measured using a Gamry Reference 600 potentiostat/galvanostat. Electrodes were evaluated in aqueous $0.2 \mathrm{M}$ potassium hydrogen phthalate (KHP) with $0.5 \mathrm{M} \mathrm{K}_{2} \mathrm{SO}_{4}$ supporting electrolyte, buffered to $\mathrm{pH} 4.5$ using $\mathrm{KOH}$. This electrolyte acted as a stable $\mathrm{pH}$ buffer, produced a stable reversible hydrogen electrode (RHE) potential, and represented the best compromise between activity and stability for all of the systems tested in this work. 
Electrochemical experiments were performed in a twocompartment Pyrex cell equipped with a flat Pyrex window and with a saturated calomel electrode $(\mathrm{SCE})$ reference $\left(E^{\circ \prime}=\right.$ $+0.244 \mathrm{~V}$ vs. NHE, CH Instruments). A Pt mesh counter electrode was contained in a separate compartment that was isolated from the main cell compartment by a fine porosity frit. All of the electrochemical data were collected with fast stirring of the solution, to minimize mass transport effects and rapidly remove nucleated bubbles from the electrode surface.

The electrolyte was constantly bubbled with research grade $\mathrm{H}_{2}$ (g) (AirLiquide) to maintain a constant RHE potential, as determined by measurement of the open-circuit potential of a platinized Pt wire before and after each set of measurements. The RHE potential was consistently measured to be $-505 \pm$ $5 \mathrm{mV} v s$. SCE, in close agreement with the value predicted by the Nernst equation at $\mathrm{pH}$ 4.5. The measured RHE potential did not shift by more than $\pm 1 \mathrm{mV}$ over the course of several hours of measurements.

Electrodes were tested using cyclic voltammetry $(\mathrm{CV})$ or linear sweep voltammetry (LSV), both at a scan rate of $20 \mathrm{mV} \mathrm{s}^{-1}$. The current density versus potential $(J-E)$ data were not corrected for any uncompensated resistance losses or for concentration overpotentials. In the case of $\mathrm{CV}$, forward and reverse sweeps generally showed minimal hysteresis. Where hysteresis was observed, the data collected while sweeping from negative toward positive potentials (reverse sweep) were found to correspond better to steady-state polarization measurements, and thus were used for final analysis. LSV measurements generally began at a potential $300-800 \mathrm{mV}$ negative of RHE, and ended just positive of where the electrode began to pass anodic current. The potential limits for cyclic voltammetry were set to prevent the passage of large anodic current densities. These precautions were taken to prevent the Si surface from oxidizing and to minimize anodic stripping of the non-noble catalyst particles from the electrode surface.

The photoelectrode performance was evaluated under simulated sunlight supplied by a home-built ELH-type tungstenhalogen light source. The light source was placed at a distance from the electrochemical cell sufficient to generate an incoming photon flux equivalent to 1 Sun illumination, as measured by a $\mathrm{Si}$ photodiode (Thorlabs) that was calibrated relative to a NISTtraceable standard (Solarex).

\section{Results}

\section{A. Composition and morphology of the deposited electrocatalysts}

1. SEM data for Ni, Ni-Mo and Pt electrocatalysts deposited onto planar Si electrodes. All three of the materials deposited on planar Si electrodes as nanoparticles, as indicated by SEM data (Fig. 2). The Ni particles nucleated and rapidly grew to $\sim 100 \mathrm{~nm}$ in diameter, and coalesced into a continuous film as the deposition time increased from 0.5 to $5 \mathrm{~s}$. Electrodeposition of Ni-Mo produced somewhat smaller nanoparticles and smaller interparticle distances than were observed for electrodeposited Ni. When the deposition time for the Ni-Mo films was increased from a few seconds to several minutes, the particles did not coalesce into a continuous layer, but instead formed multilayers composed of progressively larger agglomerates of particles. These multilayers remained porous, as underlying layers of the electrodeposited Ni-Mo film were visible in the SEM.

In contrast, the electroless deposition of $\mathrm{Pt}$ produced a discontinuous nanoparticulate film. ${ }^{21}$ Increases in the deposition time, from 2 to $8 \mathrm{~min}$, increased the density of Pt nanoparticles, eventually creating large island-like agglomerates that began to flake off of the Si surface. Deposition of Pt by electron beam evaporation, even of a nominally $\sim 1 \mathrm{~nm}$ thick coating, gave a film that was difficult to image clearly by SEM, but resulted in enhanced catalytic activity for the HER that was consistent with the deposition of Pt (vide infra).

2. TEM data for electrocatalysts deposited onto planar p-type Si electrodes. TEM analysis of the Ni-Mo (Fig. 3) and Ni (see ESI $\dagger$ ) films indicated that the mean crystallite sizes in the deposits were $\sim 5 \pm 2$ and $\sim 10 \pm 5 \mathrm{~nm}(1 \sigma)$, respectively. Electron diffraction and EDS indicated that the Ni-Mo film was single phase, with a lattice spacing that closely matched the Ni facecentered-cubic lattice, and with a bulk composition of $\sim 85 \% \mathrm{Ni} /$ $\sim 15 \%$ Mo.

3. SEM data for electrocatalysts deposited onto Si microwire arrays. As probed by SEM, on $\mathrm{p}^{+}-\mathrm{Si}$ microwire arrays, $\mathrm{Ni}, \mathrm{Ni}-$ Mo, and Pt produced homogeneous and conformal deposits over the entire surface of the microwires (Fig. 4). In contrast, on p-Si microwires, the deposits were only evident by SEM on the bottom halves of the wires, but EDS analysis indicated that catalyst had deposited over the entire wire surface.

\section{B. Dark current-density vs. potential behavior of electrodeposited catalysts on degenerately doped planar Si electrodes}

Representative polarization data for $\mathrm{Ni}, \mathrm{Ni}-\mathrm{Mo}$, and $\mathrm{Pt}$ on planar $\mathrm{p}^{+}$-Si electrodes are depicted in Fig. 5 and are summarized in Table 1. The aggregate activities of the various catalyst materials were assessed quantitatively by comparing the cathodic current density observed at a HER overpotential of $100 \mathrm{mV}$ $\left(J_{\text {dark,100 }}\right){ }^{22}$ This measure of activity included both the electronic and geometric (surface area) contributions to the hydrogen evolution activity of the various deposits. ${ }^{23}$ Using this metric, the activities for the three catalyst systems on planar $\mathrm{p}^{+}$-Si electrodes increased in the order $\mathrm{Ni}<\mathrm{Ni}-\mathrm{Mo} \leq \mathrm{Pt}$.

$\mathrm{Ni}$ consistently showed the most negative onset potential of appreciable cathodic current density, reaching only $J=$ $-0.12 \mathrm{~mA} \mathrm{~cm}^{-2}$ at $E=-100 \mathrm{mV} v s$. RHE when Ni had been electrodeposited for $5 \mathrm{~s}$ on to the $\mathrm{p}^{+}$-Si surface. Shorter deposition times produced lower catalytic activity, and longer deposition times produced relatively smooth, continuous Ni films that had similar activities to the $\mathrm{Ni}$ data shown in Fig. 5. The $J-E$ behavior observed herein for $\mathrm{Ni}$ on $\mathrm{Si}$ is very close to the behavior observed previously for the HER of Ni-plated $\mathrm{Fe}$ electrodes. ${ }^{24}$

$\mathrm{Ni}-\mathrm{Mo}$ alloy films on planar $\mathrm{p}^{+}-\mathrm{Si}$ gave $J-E$ responses that exhibited increasing catalytic activities over several min of deposition. Deposition for 20-30 s produced films with a single layer (as observed by SEM) of Ni-Mo deposit, and produced $\sim 2 \mathrm{~mA} \mathrm{~cm} \mathrm{~cm}^{-2}$ of cathodic current density for the HER at 


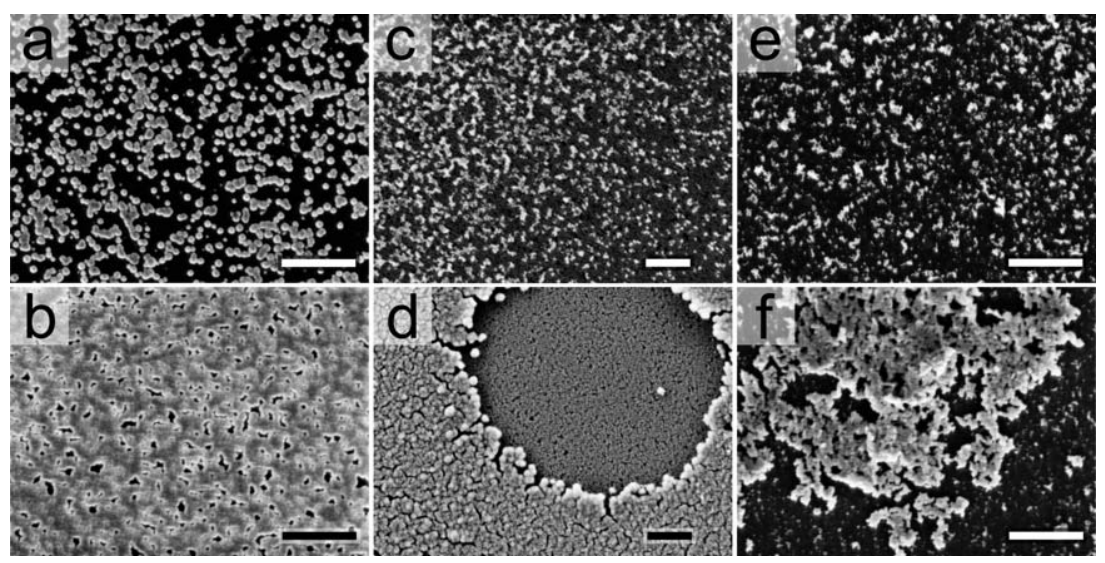

Fig. 2 Scanning electron micrographs of catalyst particles on planar Si surfaces: (a) Ni deposited for $0.5 \mathrm{~s}$; (b) Ni deposited for $1.0 \mathrm{~s}$; (c) Ni-Mo deposited for $30 \mathrm{~s}$; (d) Ni-Mo deposited for $90 \mathrm{~s}$; (e) electroless Pt deposited for $360 \mathrm{~s}$ (f) same as e, but showing a Pt agglomerate. The scale bar in each panel is $1 \mu \mathrm{m}$.
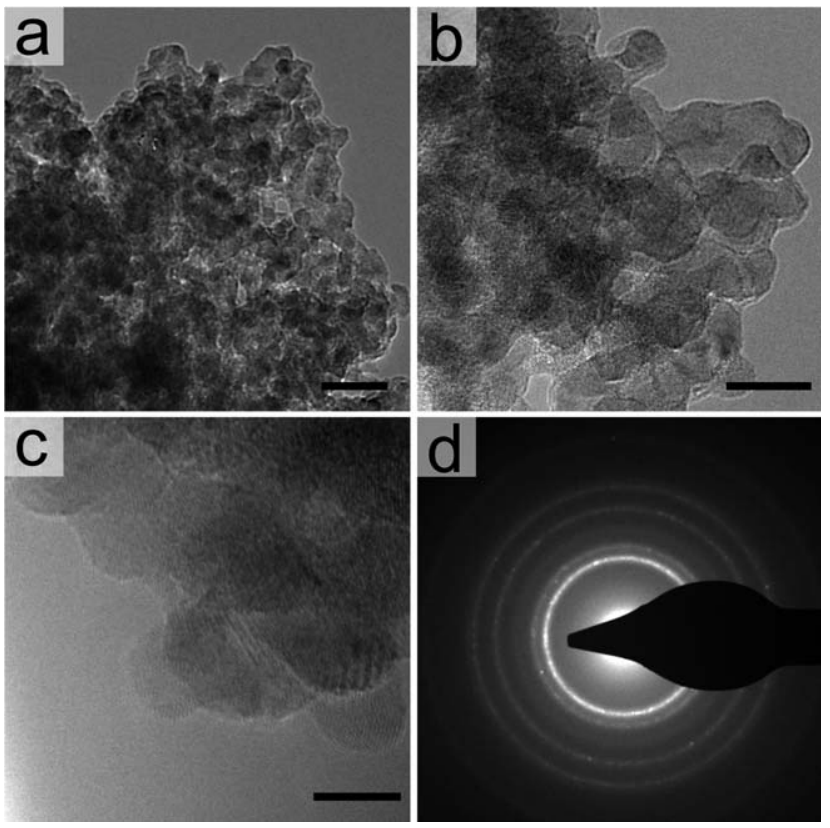

Fig. 3 (a-c) TEM images and (d) electron diffraction pattern of a $\mathrm{Ni}-$ Mo film that was electrodeposited onto a $\mathrm{p}^{+}-\mathrm{Si}$ electrode. The images indicate that the Ni-Mo deposits were agglomerates of $<10 \mathrm{~nm}$ crystallites. Scale bars: (a) $20 \mathrm{~nm}$; (b) $10 \mathrm{~nm}$; (c) $5 \mathrm{~nm}$.

$E=-100 \mathrm{mV} v s$. RHE. Deposition for $>30$ s produced films that had a multilayer structure and yielded HER cathodic current densities of $>5 \mathrm{~mA} \mathrm{~cm}^{-2}$ at $E=-100 \mathrm{mV} v s$. RHE.

The two techniques used to deposit the Pt electrocatalyst yielded different $J-E$ responses on planar $\mathrm{p}^{+}-\mathrm{Si}$ electrodes. The onset of cathodic current obtained for the electroless deposition of a Pt electrocatalyst deposit was similar to that observed for $\mathrm{Ni}-\mathrm{Mo}$ that had been deposited on $\mathrm{p}^{+}-\mathrm{Si}$ for $90 \mathrm{~s}$, giving nearly $-5 \mathrm{~mA} \mathrm{~cm}^{-2}$ at $E=-100 \mathrm{mV}$ vs. RHE. As the potential was scanned more negative relative to RHE, the electroless Pt films produced a very linear $J-E$ electrocatalytic response, indicating resistive behavior. In contrast, $\mathrm{Pt}$ films that had been deposited by electron-beam evaporation, although nominally only $\sim 1 \mathrm{~nm}$ thick, were highly active electrocatalysts on $\mathrm{p}^{+}-\mathrm{Si}$ for the HER, reaching $J=-20-30 \mathrm{~mA} \mathrm{~cm}{ }^{-2}$ at $E=-100 \mathrm{mV}$ vs. RHE. Furthermore, at higher cathodic current densities, the e-beam deposited Pt films showed the expected exponential response rather than the linear response that was observed for electroless $\mathrm{Pt}$ deposits on $\mathrm{p}^{+}-\mathrm{Si}$.

\section{Dark current-density vs. potential behavior of} electrodeposited catalysts on degenerately doped $\mathrm{Si}$ microwire array electrodes

The catalytic activities of $\mathrm{Ni}, \mathrm{Ni}-\mathrm{Mo}$, and $\mathrm{Pt}$, respectively, were considerably higher, but exhibited the same trend in relative activity, on $\mathrm{p}^{+}-\mathrm{Si}$ microwire arrays relative to the activity on planar $\mathrm{p}^{+}-\mathrm{Si}$ electrode surfaces (Fig. 6, Table 1). The $J-E$ response of electroless $\mathrm{Pt}$ deposits was closer to that of e-beam $\mathrm{Pt}$ deposits on $\mathrm{p}^{+}-\mathrm{Si}$ microwires than on the planar $\mathrm{p}^{+}-\mathrm{Si}$ electrodes, but the $J-E$ response was still relatively linear at large cathodic current densities.

Fast stirring and continuous bubbling of $\mathrm{H}_{2}(\mathrm{~g})$ through the solution were required to obtain reproducible $J-E$ responses for planar and microwire array $\mathrm{p}^{+}-\mathrm{Si}$ electrodes. The $J-E$ data generally proceeded cleanly through $J=0$ at $E=0$ vs. RHE under these conditions, but only using the LSV technique, beginning at negative potentials and proceeding in the positive direction. An exception was the case of Ni-Mo alloy electrodeposited onto $\mathrm{p}^{+}-\mathrm{Si}$ microwires, which often passed through $J=$ 0 at $E<0 v s$. RHE, similar to the behavior observed previously with bulk Ni-Mo alloy cathodes as well as with electrodeposited $\mathrm{Ni}-\mathrm{Mo}-\mathrm{Cd}$ films. ${ }^{24}$

\section{Photoelectrochemical behavior of electrocatalysts on p-Si electrodes}

Six metrics were used to evaluate the photoelectrochemical performance of $\mathrm{Ni}, \mathrm{Ni}-\mathrm{Mo}$, and $\mathrm{Pt}$, respectively, as electrocatalysts on illuminated planar $\mathrm{p}-\mathrm{Si}$ or $\mathrm{p}-\mathrm{Si}$ microwire array photocathodes in contact with $\mathrm{pH}=4.5$ aqueous solutions (Fig. 7, 8, Table 2). These metrics [eqn (1) to (6)] were:

$$
V_{\mathrm{oc}}=\left|E_{\mathrm{oc}}-E_{\mathrm{RHE}}\right|
$$




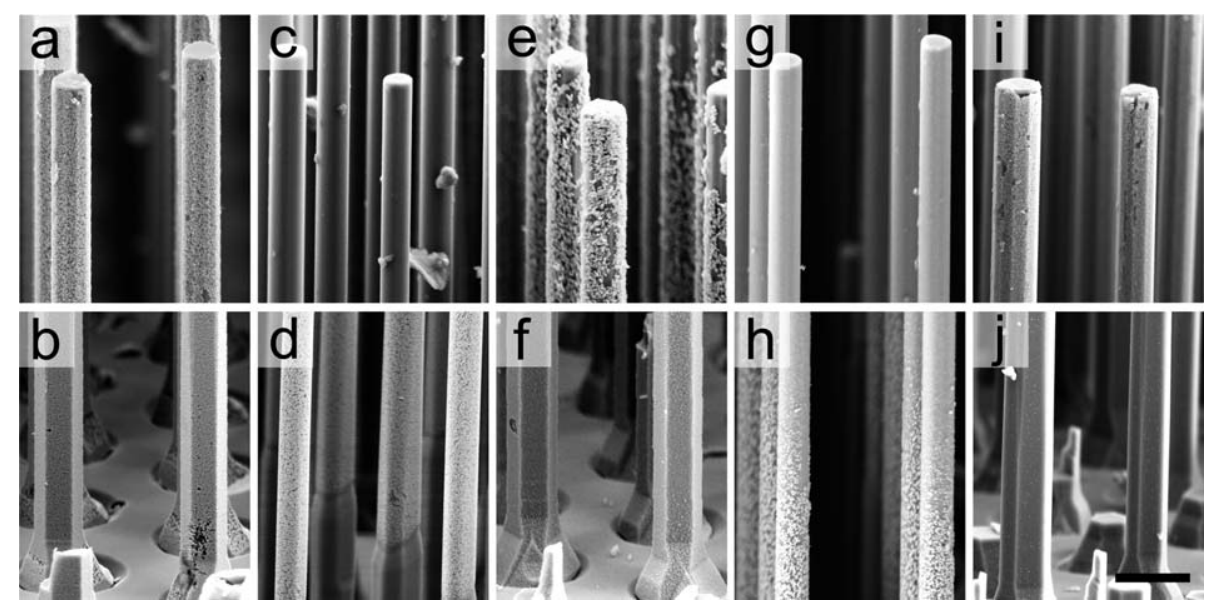

Fig. 4 Scanning electron micrographs of catalyst particles on Si microwire tops (above) and bases (below): (a, b) p ${ }^{+}-\mathrm{Si}$ deposited with Ni for $5 \mathrm{~s}$; (c, d) p-

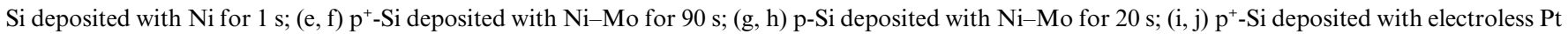
for $360 \mathrm{~s}$. The scale bar in (j) is $3 \mu \mathrm{m}$, and applies to all panels.

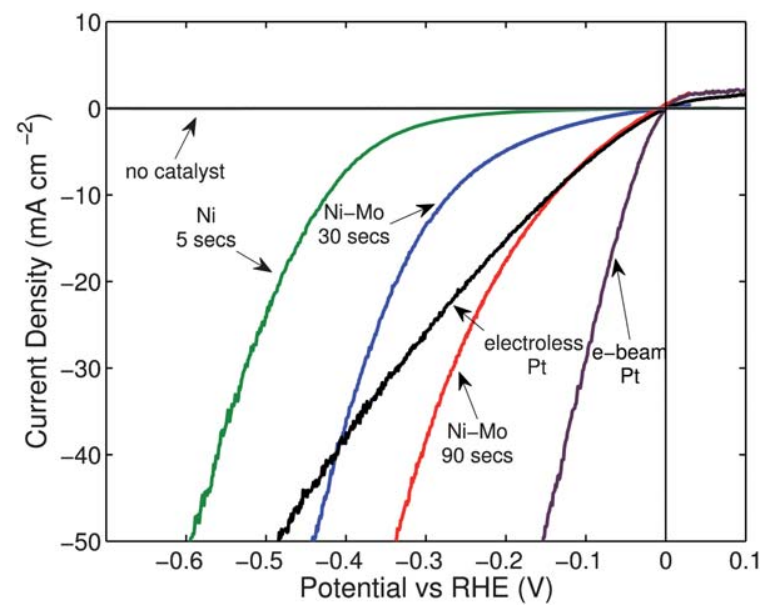

Fig. 5 Polarization data of the HER activities of various catalysts on planar $\mathrm{p}^{+}-\mathrm{Si}$ electrodes. The total deposition times for electrodeposited catalyst films are specified. Data were collected at $\mathrm{pH}=4.5$, and are referenced to the RHE potential.

$$
\begin{gathered}
J_{\text {light }, 100}=\left.J\right|_{E_{\mathrm{oc}}}-100 \mathrm{mV} \\
J_{\mathrm{sc}}=\left.J\right|_{E_{\mathrm{RHE}}} \\
J_{\mathrm{ph}}=\left.J\right|_{E_{\mathrm{RHE}}-0.4 \mathrm{~V}} \\
f f=\frac{P_{\max }}{V_{\mathrm{oc}} \cdot\left|J_{\mathrm{sc}}\right|} \\
\eta_{\mathrm{H}_{2}}=\frac{P_{\mathrm{max}}}{P_{\text {in }}}=\frac{f f \cdot V_{\mathrm{oc}} \cdot\left|J_{\mathrm{sc}}\right|}{P_{\text {in }}}
\end{gathered}
$$

a) the open-circuit voltage ( $V_{\text {oc }}$, eqn (1)), which indicates, relative to RHE, the maximum free energy that can be extracted from the photoelectrode, where $E_{\mathrm{oc}}$ is the potential at which the photoelectrode passed no current; b) the apparent aggregate catalytic

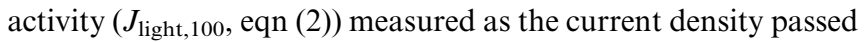
at a potential $100 \mathrm{mV}$ negative of $E_{\mathrm{oc}} ;$ c) the short-circuit current density $\left(J_{\text {sc }}\right.$, eqn (3)), the current density at $E=0 \mathrm{~V} v s$. RHE; d) the light-limited photocurrent density $\left(J_{\mathrm{ph}}\right.$, eqn (4)), measured as the current density at $E=-0.40 \mathrm{~V} v s$. RHE; e) the fill factor ( $f f$, eqn (5)), a measure of the "squareness" of the $J-E$ response, where $P_{\max }$ is the maximum product of $|J|$ and $E$; and $\mathrm{f}$ ) the thermodynamic efficiency for production of $\mathrm{H}_{2}(\mathrm{~g})\left(\eta_{\mathrm{H}_{2}}\right.$, eqn (6)), where $P_{\text {in }}$ is the incoming light intensity, $100 \mathrm{~mW} \mathrm{~cm}^{-2}$ for AM 1.5 simulated sunlight.

1. Apparent catalytic activities. The apparent catalytic activities for $\mathrm{p}$-Si photoelectrodes, both in planar and microwire array forms, followed the same order, $\mathrm{Ni}<\mathrm{Ni}-\mathrm{Mo} \leq \mathrm{Pt}$, as was observed for these catalysts on un-illuminated $\mathrm{p}^{+}-\mathrm{Si}$ electrodes. In general, however, the photoelectrodes required a more negative potential (relative to $E_{\mathrm{oc}}$ ) to produce a given current density than dark electrodes (relative to $E_{\mathrm{RHE}}$ ) that had been deposited with the same catalyst material. The exception was $\mathrm{Ni}$, which exhibited a somewhat more rapidly increasing onset of cathodic current density on illuminated p-Si photoelectrodes than on dark $\mathrm{p}^{+}$-Si electrodes, especially when Ni had been deposited onto $\mathrm{p}-\mathrm{Si}$ microwire array photocathodes.

2. Open-circuit potentials. The $V_{\mathrm{oc}}$ values for the photocathodes followed the order $\mathrm{Ni}-\mathrm{Mo}<\mathrm{Ni}<\mathrm{Pt}$ on both planar and microwire arrays of $\mathrm{p}-\mathrm{Si}$. Additionally, for electrodeposited $\mathrm{Ni}$, the $V_{\text {oc }}$ values were smaller by $>100 \mathrm{mV}$ on p-Si microwire arrays than on planar p-Si electrodes. Interestingly, the $V_{\mathrm{oc}}$ values obtained for $\mathrm{Pt}$ on $\mathrm{p}$-Si photoelectrodes were dependent on the method of $\mathrm{Pt}$ deposition. Electron-beam evaporated $\mathrm{Pt}$ films yielded ohmic contacts to planar $\mathrm{p}-\mathrm{Si}$, resulting in high catalytic activity but no photovoltage, whereas electroless $\mathrm{Pt}$ deposition gave the largest photovoltages observed for any of the electrocatalytic deposits studied herein on both p-Si planar and microwire array electrodes.

3. Short-circuit photocurrent densities. The observed $J_{\mathrm{sc}}$ values for planar $\mathrm{p}$-Si photoelectrodes generally were between $-10 \mathrm{~mA} \mathrm{~cm}^{-2}$ and $-25 \mathrm{~mA} \mathrm{~cm}^{-2}$, depending on the length of time that the catalyst had been deposited. These $J_{\text {sc }}$ values correspond to somewhat lower apparent quantum yields than have been 
Table 1 Figures of merit for $\mathrm{p}^{+}-\mathrm{Si}$ dark electrocatalysis

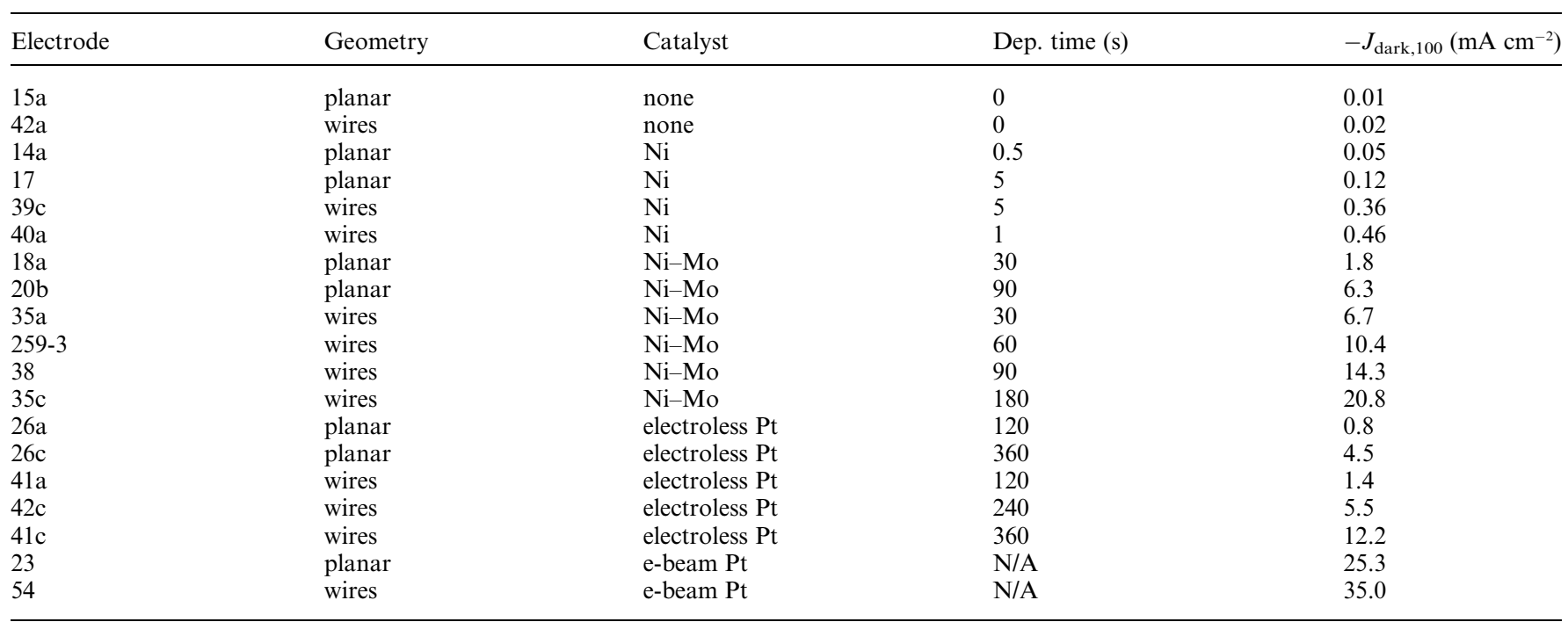

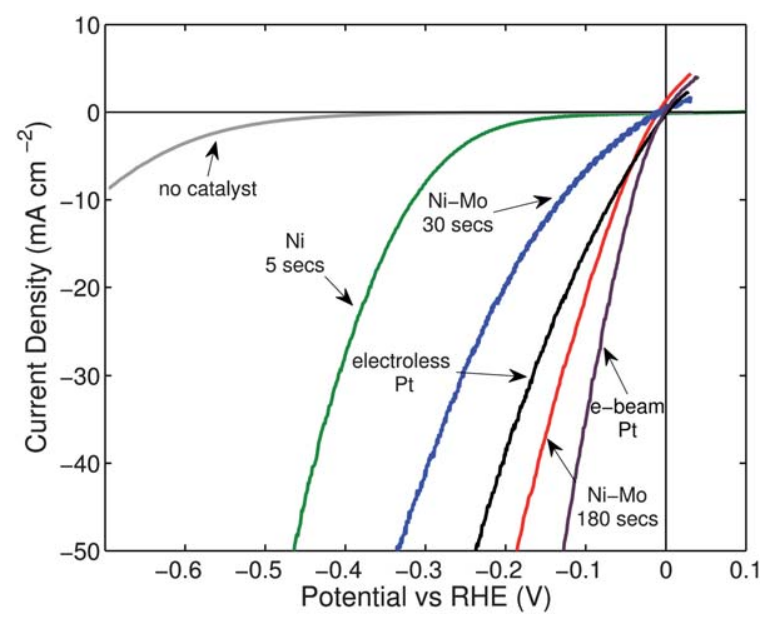

Fig. 6 Polarization data of the HER activities of various catalysts on $\mathrm{p}^{+}$$\mathrm{Si}$ microwire electrodes. The total deposition times for electrodeposited catalyst films are specified. Data were collected at $\mathrm{pH}=4.5$, and are referenced to the RHE potential.

observed for $\mathrm{p}$-Si photoelectrodes under a controlled, monochromatic photon flux in contact with an aqueous methyl viologen $\left(\mathrm{MV}^{2+/+}\right)$ redox system, ${ }^{25}$ indicating that the catalyst particles absorbed and/or reflected some of the incident light.

$J_{\text {sc }}$ values for $\mathrm{p}$-Si microwire array photoelectrodes were between $-8 \mathrm{~mA} \mathrm{~cm}^{-2}$ and $-15 \mathrm{~mA} \mathrm{~cm} \mathrm{~cm}^{-2}$ at normal incidence. These values increased in magnitude when the electrode was tilted by $\sim 35^{\circ}$ relative to the propagation vector of the incident optical beam. These $J_{\mathrm{sc}}$ values are close to the values that have been reported for $\mathrm{p}$-Si microwire arrays in contact with $\mathrm{MV}^{2+/+}(\mathrm{aq})$, as well as for HER using a Pt electrocatalyst, suggesting minimal net absorption or reflection by the catalyst particles. ${ }^{12,25}$

4. Overall photoelectrode performance. The thermodynamically based light-to- $\mathrm{H}_{2}$ photoelectrode efficiencies ranged from $\sim 0.2 \%$ to $\sim 1 \%$, and increased in the order $\mathrm{Ni} \approx \mathrm{Ni}-\mathrm{Mo}<\mathrm{Pt}$. Because the higher $V_{\text {oc }}$ values for $\mathrm{Ni}$-decorated electrodes were

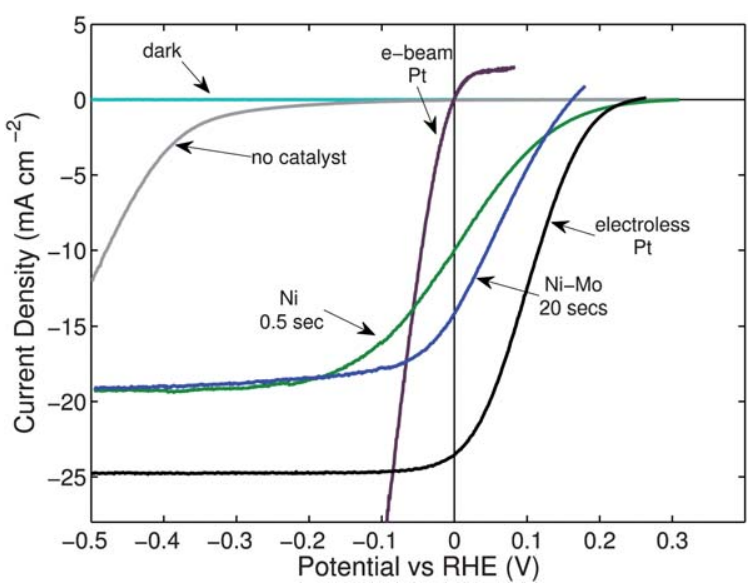

Fig. 7 Polarization data of the HER activities of various catalysts on illuminated planar p-Si photoelectrodes. The total deposition times for electrodeposited catalyst films are specified. Data were collected at $\mathrm{pH}=$ 4.5 , and are referenced to the RHE potential.

offset by higher catalytic activities for $\mathrm{Ni}-\mathrm{Mo}$, Ni and $\mathrm{Ni}-\mathrm{Mo}$ coated Si photocathodes exhibited similar overall efficiencies of $0.2-0.4 \%$. The fill factors for the Ni-Mo deposited photoelectrodes were somewhat higher than fill factors for electrodes that had Ni deposits, which is also consistent with the higher catalytic activity of $\mathrm{Ni}-\mathrm{Mo}$ relative to $\mathrm{Ni}$. P-type $\mathrm{Si}$ microwire array photoelectrodes gave overall thermodynamically based efficiencies for $\mathrm{H}_{2}$ production that were similar to those of the corresponding planar p-Si electrodes, due to the generally lower photocurrent densities of the microwire arrays compensated by higher fill factors relative to the planar $\mathrm{p}-\mathrm{Si}$ electrodes.

\section{Discussion}

\section{A. Deposition of the electrocatalysts}

The Ni-Mo alloy deposition bath was based on an acidic Ni sulfamate plating bath, ${ }^{20}$ rather than the widely used alkaline citrate or pyrophosphate baths. ${ }^{26-28}$ The sulfamate solution 


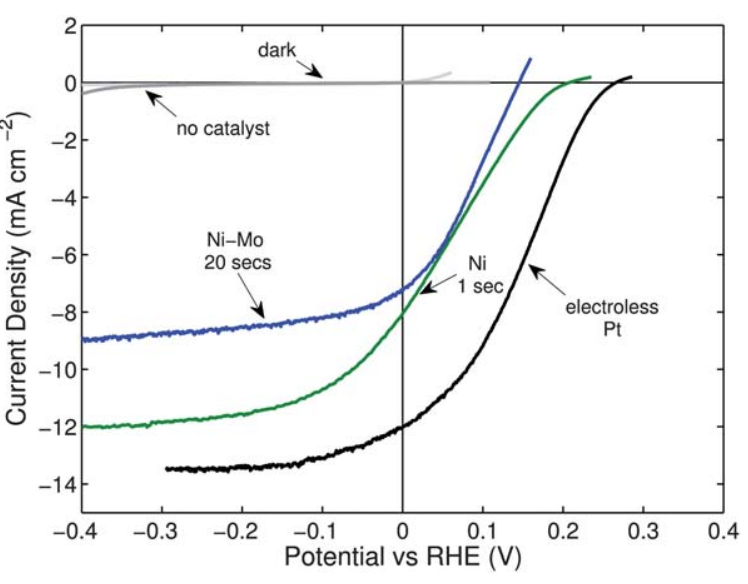

Fig. 8 Polarization data of the HER activities of various catalysts on illuminated $\mathrm{p}$-Si microwire array photoelectrodes. The total deposition times for electrodeposited catalyst films are specified. Data were collected at $\mathrm{pH}=4.5$, and are referenced to the RHE potential.

avoided the instability of the Si surface toward oxidation under alkaline conditions. Use of alkaline Ni-Mo plating baths yielded inconsistent results, with the resulting deposits showing poor adhesion to the Si surface.

The Ni-Mo/sulfamate plating bath was similar to existing bath formulations, in that it involved the addition of $\mathrm{Na}_{2} \mathrm{MoO}_{4}$ to a Ni plating solution. However, the relative amount of Mo was much lower ( $1.5 \mathrm{~mol} \%$ Mo relative to total metal content) in the sulfamate bath compared to that contained in alkaline $\mathrm{Ni}-$ Mo deposition baths (>10\% Mo). ${ }^{26}$ Increases in the concentration of $\mathrm{MoO}_{4}{ }^{2-}$ beyond $1.5 \%$ resulted in films that had poor adherence onto the $\mathrm{Si}$ electrode surfaces and also exhibited low activity for the HER. The Ni-Mo/sulfamate solution was stable over a period of months, with no evidence of changes in $\mathrm{pH}$ or formation of "molybdenum blue" precipitates..$^{29,30}$

The formation of active $\mathrm{Ni}-\mathrm{Mo}$ catalyst films required the use of relatively large cathodic deposition current densities $\left(>10 \mathrm{~mA} \mathrm{~cm}{ }^{-2}\right)$. At these current densities, bubbles were observed on the electrode surface, consistent with the simultaneous evolution of $\mathrm{H}_{2}$ and deposition of Ni-Mo. The production of $\mathrm{H}_{2}(\mathrm{~g})$ is consistent with a previously proposed deposition mechanism in which evolved $\mathrm{H}_{2}(\mathrm{~g})$ reduces the intermediate $\mathrm{Ni}-$ Mo mixed oxide to a neutral alloy [eqn (7) to (10)]. . $^{31}$

$$
\begin{gathered}
\mathrm{MoO}_{4}^{2-}+4 \mathrm{H}^{+} \stackrel{2 \mathrm{e}^{-}}{\longrightarrow} \mathrm{MoO}_{2}+2 \mathrm{H}_{2} \mathrm{O} \\
\mathrm{Ni}^{2+}+\mathrm{MoO}_{2} \stackrel{2 \mathrm{e}^{-}}{\longrightarrow} \mathrm{NiMoO}_{2} \\
2 \mathrm{HA} \stackrel{2 \mathrm{e}^{-}}{\longrightarrow} \mathrm{H}_{2}+2 \mathrm{~A}^{-} \\
2 \mathrm{H}_{2}+\mathrm{NiMoO}_{2} \rightarrow \mathrm{NiMo}+2 \mathrm{H}_{2} \mathrm{O}
\end{gathered}
$$

Increases in the cathodic deposition current density, to $100 \mathrm{~mA}$ $\mathrm{cm}^{-2}$, resulted in thick, gray-black deposits that exhibited poor HER activity, and that readily dissolved in acidic solution. The behavior at high deposition current densities is consistent with the precipitation of $\mathrm{Ni}$ hydroxides, due to the increase in local $\mathrm{pH}$ effected by the vigorous evolution of $\mathrm{H}_{2}(\mathrm{~g})$ in the poorly buffered plating solution.

The relatively long times required to deposit single layers of $\mathrm{Ni}-\mathrm{Mo}$, compared to the deposition of $\mathrm{Ni}$ from the Ni/sulfamate bath, are also consistent with the co-evolution of $\mathrm{H}_{2}(\mathrm{~g})$ during the deposition of Ni-Mo from the sulfamate solution. The deposition current efficiency of Ni-Mo from the sulfamate solution was $<5 \%$, as compared to nearly $100 \%$ under the noted conditions for $\mathrm{Ni}$ from the sulfamate solution (see ESI $\dagger$ ). Consequently, the resulting films of Ni-Mo particles were generally discontinuous and contained micron-scale holes or inhomogeneities, likely due to $\mathrm{H}_{2}(\mathrm{~g})$ bubbles blocking the surface from access to the plating solution.

\section{B. Relative electrocatalytic activities}

When polished to minimize variations in relative surface area, a Ni-Mo alloy has been shown to produce slightly higher fundamental HER activity than $\mathrm{Ni}^{19,24,32}$ but lower HER activity than bright (smooth) $\mathrm{Pt}^{33}$ Relative to smooth bulk Ni-Mo surfaces, enhanced HER activity has been documented for electrodeposited Ni-Mo, as evidenced by an increased exchange current density and a decreased Tafel slope, apparently due to micro/nanostructuring of the electrocatalytic deposits. ${ }^{24}$

Table 2 Figures of merit for photoelectrodes

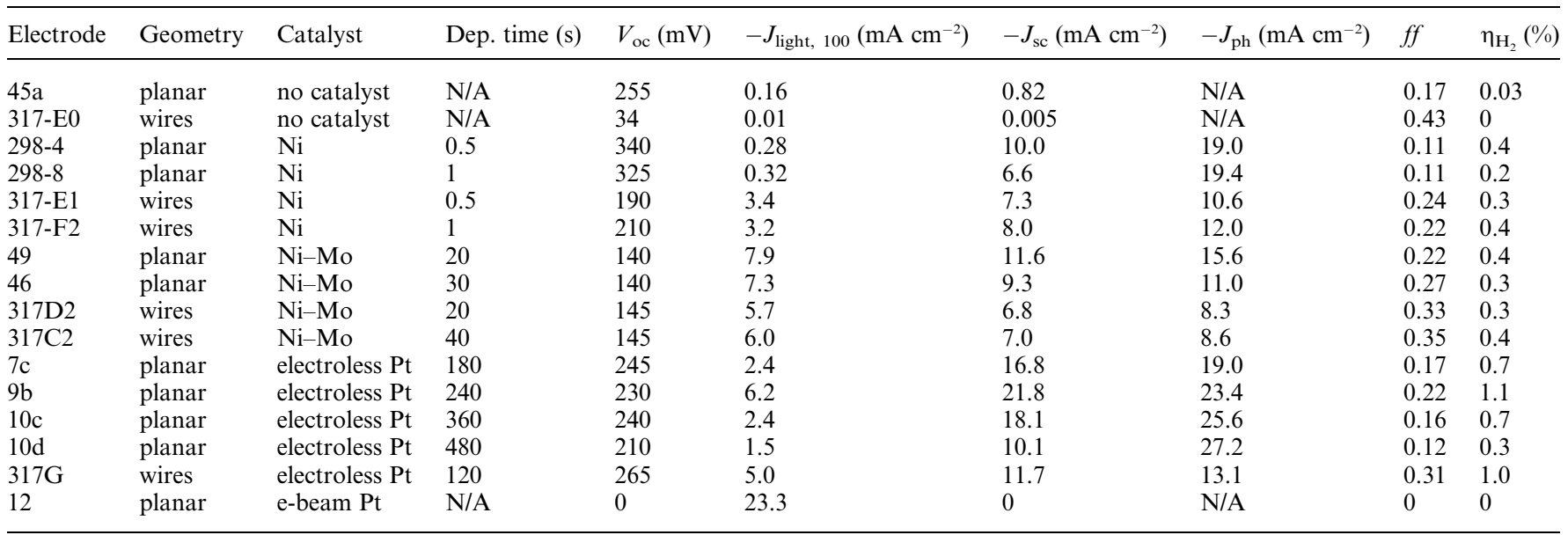


Notably, Ni-Mo coatings designed for maximum surface roughness have been reported to exhibit higher HER activities than smooth $\mathrm{Pt}$, and are reported to be stable for $>1$ year in contact with alkaline electrolyte. ${ }^{34,35}$

When used as a catalyst on Si photoelectrodes, the maximum acceptable thickness (and hence roughness) of Ni-Mo is limited by the requirement of minimizing absorption of the incoming light. The observed order of catalyst activity on $\mathrm{Si}$ cathodes, $\mathrm{Ni}<$ $\mathrm{Ni}-\mathrm{Mo}<\mathrm{Pt}$ (provided that the Pt was not deposited by a method that gave rise to resistive behavior), is thus in accord with expectations. For all of the catalysts deposited on electrodes of nominally the same projected area, the HER activities observed on a Si microwire array exceeded those on planar Si electrodes, consistent with the increased amount of catalyst per projected surface area on the microwire arrays relative to compact, planar electrode surfaces.

\section{Degenerately doped dark Si electrode/catalyst systems}

Relatively short electrodeposition times were required to reach maximum HER activity of $\mathrm{Ni}$ on $\mathrm{p}^{+}-\mathrm{Si}$, owing in part to the high deposition current efficiency of $\mathrm{Ni}$ on $\mathrm{Si}$. Deposition times $<1 \mathrm{~s}$ produced a discontinuous network of $\mathrm{Ni}$ particles, whereas longer times caused the Ni particles to coalesce into a smooth film. The increase in surface coverage of these smooth films was offset somewhat by a decrease for each particle of the area exposed to the electrolyte, so the catalytic activity increased only slightly, to a plateau, after a few s of deposition.

In contrast, when deposited for long periods of time, $\mathrm{Ni}-\mathrm{Mo}$ did not produce coalescing, smooth films. Instead, Ni-Mo deposited in a multilayer structure that had a high surface roughness, which resulted from the small crystallite size of the deposits. The activity toward the HER for Ni-Mo films on $\mathrm{Si}$ therefore increased monotonically, up to rather long total deposition times. The Ni-Mo deposits thus provided relatively higher activity than pure $\mathrm{Ni}$, likely due to a combination of slightly higher fundamental activity and substantially enhanced surface area.

Pt films that were produced by electroless deposition exhibited the highest activity after 4-6 min of deposition from a $1 \mathrm{mM} \mathrm{Pt}$ (Iv) salt solution. The resulting morphology was a nanoparticulate network similar to that produced by the short-time deposition of Ni-Mo or Ni. However, the catalytic behavior of electroless $\mathrm{Pt}$ on planar $\mathrm{p}^{+}-\mathrm{Si}$ at $>10 \mathrm{~mA} \mathrm{~cm}^{-2}$ was dominated by a large series resistance. This resistance was likely due to the formation of a barrier layer between the $\mathrm{Si}$ surface and the $\mathrm{Pt}$ nanoparticles.

A mechanism for the electroless deposition of Pt on Si involves the sacrificial oxidation of surface $\mathrm{Si}$, and subsequent removal by HF [eqn (11) and (12)]. ${ }^{21}$

$$
\begin{gathered}
\mathrm{H}_{2} \mathrm{PtCl}_{6}+\mathrm{Si}^{0}+2 \mathrm{H}_{2} \mathrm{O} \rightarrow \mathrm{Pt}^{0}+\mathrm{SiO}_{2}+6 \mathrm{HCl} \\
\mathrm{SiO}_{2}+6 \mathrm{HF} \rightarrow \mathrm{H}_{2} \mathrm{SiF}_{6}+2 \mathrm{H}_{2} \mathrm{O}
\end{gathered}
$$

Some oxidized $\mathrm{Si}$ sites may not be accessible to etching by $\mathrm{HF}$, due to the presence of the Pt overlayer. As a result, the interfacial region between the $\mathrm{Si}$ and the electrolessly deposited $\mathrm{Pt}$ nanoparticles could have an insulating Si oxide, yielding the observed resistive behavior of the electrodes. This hypothesis is consistent with the observations that (a) e-beam evaporated Pt exhibited no such resistive behavior, presumably because this deposition process did not involve the chemical oxidation of $\mathrm{Si}$, and (b) electroless $\mathrm{Pt}$ deposits on $\mathrm{Si}$ microwires did not show such pronounced resistive behavior, because the greater surface roughness would provide many more parallel paths by which electrons might traverse the interface, resulting in a lower overall resistance of the catalyst-coated electrode.

XPS analysis was performed to elucidate the state of the $\mathrm{Si}$ surface under various conditions of Pt deposition (Fig. 9). A planar $\mathrm{p}^{+}$-Si sample coated with electroless $\mathrm{Pt}$, from a $1 \mathrm{mM} \mathrm{Pt}$ (Iv)/HF(aq) solution, showed markedly higher levels of oxidized Si than a bare Si control, or than a sample that had been coated with a deposit of e-beam evaporated Pt. These data strongly support the formation of an interfacial oxide on $\mathrm{Si}$ in the presence of $\mathrm{Pt}(\mathrm{IV})$ salts, which is consistent with the resistive behavior observed in the HER experiments.

The observed activity of a given electrocatalyst was higher on $\mathrm{p}^{+}-\mathrm{Si}$ microwire arrays than on planar $\mathrm{p}^{+}-\mathrm{Si}$. These higher observed activities are consistent with the increased total amount of catalyst that resulted from microstructuring of the wire array electrode. Electron microscopy also indicated that the catalyst conformally coated the entire length of the $\mathrm{p}^{+}-\mathrm{Si}$ microwires. The increase in observed activities for the $\mathrm{Ni}$ and $\mathrm{Ni}-\mathrm{Mo}$ deposits on the Si microwire arrays was comparable to the surface roughness factor $\gamma \sim 6$ of the particular Si microwire array electrodes used in this study. These observations indicate that the microstructured geometry effected a significant enhancement in the observed electrocatalytic activity. This enhancement is in addition to that provided from nanostructuring of the electrodeposited catalysts themselves, suggesting that roughness effects on the micro- and nano-scale are multiplicative (i.e. $\gamma_{\text {total }}=$ $\left.\gamma_{\text {nano }} \cdot \gamma_{\text {micro }}\right)$. The observations also indicate a relatively facile

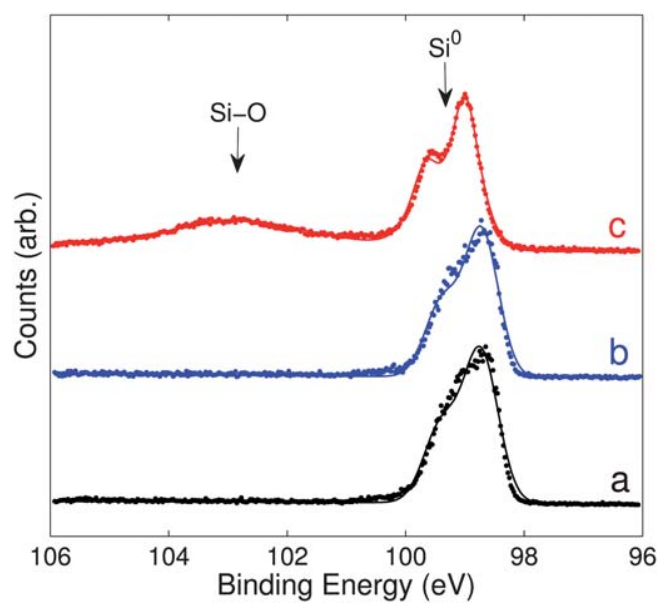

Fig. 9 XP spectra of the $\mathrm{Si} 2 \mathrm{p}$ region of three $\mathrm{p}^{+}-\mathrm{Si}$ samples: (a) control sample with no deposition; (b) coated with Pt via e-beam evaporation; (c) coated with Pt via electroless deposition. In all three cases, samples were treated in nominally the same fashion, other than the deposition conditions, and were freshly etched in buffered $\mathrm{HF}(\mathrm{aq})$ immediately before introduction into the analysis chamber. Sample (c) showed significant surface oxidation, while samples (a) and (b) showed little to no detectable signals attributable to oxidized Si. 
mass transport of reactant and product species to and from the base of the microwires. The performance of the Ni-Mo catalyst on $\mathrm{p}^{+}-\mathrm{Si}$ microwires approached the activity of e-beam evaporated $\mathrm{Pt}$ films on planar $\mathrm{Si}$, which has been shown to possess sufficient catalytic activity to enable highly efficient hydrogen production on Si $\mathrm{p}-\mathrm{n}^{+}$junction photoelectrodes. ${ }^{12}$ This remarkably high activity for a non-noble catalyst likely results from the aforementioned increase in surface area along with a relatively smaller enhancement due to alloying Ni with Mo. Previous work suggests the fundamental catalytic activity of bulk Ni-Mo alloy is relatively insensitive to the concentration of $\mathrm{Mo}^{32}$ and the fundamental (i.e. surface area normalized) activity for our coatings is being evaluated in detail at present.

\section{Photoelectrode/catalyst systems}

Despite the higher catalytic activity of $\mathrm{Ni}-\mathrm{Mo}$ relative to $\mathrm{Ni}$, planar $\mathrm{p}$-Si photoelectrodes coated with $\mathrm{Ni}$ or $\mathrm{Ni}-\mathrm{Mo}$ showed mutually similar overall, thermodynamically based, efficiencies for the conversion of incoming simulated sunlight to $\mathrm{H}_{2}(\mathrm{~g})$. This behavior primarily resulted from the lower photovoltages exhibited by $\mathrm{p}-\mathrm{Si}$ electrodes coated with $\mathrm{Ni}-\mathrm{Mo}$ relative to $\mathrm{p}-\mathrm{Si}$ photoelectrodes coated with $\mathrm{Ni}$.

The difference in photovoltage between $\mathrm{Ni}$ and $\mathrm{Ni}-\mathrm{Mo}$ coated $\mathrm{Si}$ photocathodes is consistent with the behavior expected from inherent differences in the energetics of the mixed Si-catalyst and Si-electrolyte interfaces. Both nanostructured systems are expected to operate in the regime of the "pinch-off" effect, in which the photovoltage generated by the $\mathrm{p}$-Si/catalyst/electrolyte system of an appropriate geometry is dominated by the energetics of the interfacial region that has the larger barrier between the $\mathrm{p}$-Si and the contacting phase. ${ }^{36,37}$ The geometry in which this effect is most beneficial (i.e. yielding the highest $V_{\mathrm{oc}}$ ) is one in which the metal particles are widely separated from one another and have small areas of contact with the Si. Based on images collected from electron microscopy, the Ni-Mo nanoparticles were individually smaller, but made more extensive contact and were closer together on the Si surface, than the Ni nanoparticles. Hence, the Ni-Mo catalyst coating was likely to be less "pinched off," consistent with the lower photovoltages observed for $\mathrm{Ni}-$ Mo relative to Ni deposits.

The similarity in efficiencies for light-driven $\mathrm{H}_{2}(\mathrm{~g})$ evolution between $\mathrm{p}-\mathrm{Si} / \mathrm{Ni}$ and $\mathrm{p}-\mathrm{Si} / \mathrm{Ni}-\mathrm{Mo}$ electrodes illustrates that an increased surface area of the catalyst film does not necessarily result in enhanced performance of photoelectrodes. A higher catalyst loading increases the turnover rates for a given electrode area, but also significantly influences other parameters of the system, including the interfacial energetics and the absorption of light by the semiconductor.

$\mathrm{Pt}$ films on $\mathrm{p}-\mathrm{Si}$ exhibited perhaps the most interesting behavior of any of the three tested electrocatalyst materials. Electroless Pt deposition resulted in an interfacial oxide, which inhibited electron transport through the catalyst, enabling the pinch-off condition in which the Si/electrolyte barrier dominated the photovoltage. Conversely, e-beam evaporated $\mathrm{Pt}$, with no interfacial barrier, produced sufficiently facile electron transfer through Si-Pt-electrolyte that the interfacial energetics were dominated by the ohmic contact to Pt, resulting in no photovoltage. An implication of this observed behavior is that Pt may not, in fact, be an appropriate material to couple directly with $\mathrm{Si}$ photocathodes for efficient $\mathrm{H}_{2}$ evolution, as it forces a tradeoff between high catalytic activity (clean interface) and high photovoltage (barrier layer). Additional characterization of the $\mathrm{Si} / \mathrm{Pt}$ interface, with strict control over catalyst geometry and morphology, would thus be a useful addition to the understanding of this system.

Microwire array p-Si photoelectrodes showed similar behavior to planar p-Si photoelectrodes, except that the catalytic activity was higher, and the photocurrent densities were markedly lower for the microwire array electrodes relative to the planar electrodes. The difference in observed photocurrent density is consistent with the lower photon flux absorbed by the asprepared microwire array electrodes. Studies of light absorption have revealed the origin of the lower photocurrents in $\mathrm{Si}$ microwire arrays than in planar Si samples, and have demonstrated how incorporating light scattering/randomizing elements into the wire array structures can mitigate these effects. ${ }^{38}$ Additionally, enhanced control over the interfacial energetics of the p$\mathrm{Si} /$ catalyst/electrolyte system, including identification and elimination of deleterious surficial and/or interfacial electronic states, would be beneficial to attain yet higher photovoltages than those reported herein and thus to obtain corresponding increases in the efficiency of conversion of incident optical energy into $\mathrm{H}_{2}(\mathrm{~g})$.

\section{Conclusions}

$\mathrm{Ni}, \mathrm{Ni}-\mathrm{Mo}$, and Pt catalysts have been deposited onto p-type and degenerately doped $\mathrm{p}^{+}-\mathrm{Si}$ substrates in planar and microwire geometries. The two non-noble catalysts were both sufficiently active on p-type $\mathrm{Si}$ to give a net storage of incoming photon energy in the form of $\mathrm{H}_{2}(\mathrm{~g})$. Deposition of these catalysts onto $\mathrm{Si}$ microwire arrays enhanced the apparent activities due to increases in surface area. Ni-Mo alloy showed sufficient catalytic activity on the microwire arrays to make it a promising nonnoble alternative to $\mathrm{Pt}$, but the photocurrents and photovoltages generated by as-grown p-Si microwire electrodes are insufficient to allow optimal net energy storage. Thus, if methods can be devised to increase the photovoltage generated by illuminated $\mathrm{p}$ $\mathrm{Si}_{2}(\mathrm{~g})$ evolving microwire photocathodes, Ni-Mo would be an attractive alternative to noble metals for semiconductor-coupled $\mathrm{H}_{2}(\mathrm{~g})$ evolution from sunlight.

\section{Acknowledgements}

This work was supported by the National Science Foundation (NSF) Powering the Planet Center for Chemical Innovation (CCI), Grants CHE-0802907 and CHE-0947829, and by the Molecular Materials Research Center of the Beckman Institute at the California Institute of Technology. The authors would like to acknowledge Joseph Beardslee for assistance with XPS analysis. JRM would like to thank the Department of Energy, Office of Science, for a graduate research fellowship. SWB gratefully acknowledges fellowship support from the Kavli Nanoscience Institute.

\section{Notes and references}

1 N. S. Lewis and D. G. Nocera, Proc. Natl. Acad. Sci. U. S. A., 2006, 103, 15729-15735. 
2 N. Lewis, G. Crabtree, A. Nozik, M. Wasielewski and P. Alivisatos, DOE BES report on basic energy sciences workshop: Basic research needs for solar energy utilization, 2005, http://www.er.doe.gov/bes/ reports/abstracts.html\#SEU.

3 M. Walter, E. Warren, J. McKone, S. Boettcher, M. Qixi, L. Santori and N. Lewis, Chem. Rev., 2010, 110, 6446-6473.

4 A. Heller and R. G. Vadimsky, Phys. Rev. Lett., 1981, 46, 1153-1156.

5 R. N. Dominey, N. S. Lewis, J. A. Bruce, D. C. Bookbinder and M. S. Wrighton, J. Am. Chem. Soc., 1982, 104, 467-482.

6 R. E. Rocheleau, E. L. Miller and A. Misra, Energy Fuels, 1998, 12, $3-$ 10.

7 O. Khaselev and J. A. Turner, Science, 1998, 280, 425-427.

8 B. M. Kayes, H. A. Atwater and N. S. Lewis, J. Appl. Phys., 2005, 97, 114302.

9 B. M. Kayes, M. A. Filler, M. C. Putnam, M. D. Kelzenberg, N. S. Lewis and H. A. Atwater, Appl. Phys. Lett., 2007, 91, 103110.

10 J. M. Spurgeon, K. E. Plass, B. M. Kayes, B. S. Brunschwig, H. A. Atwater and N. S. Lewis, Appl. Phys. Lett., 2008, 93, 032112.

11 M. C. Putnam, S. W. Boettcher, M. D. Kelzenberg, D. B. TurnerEvans, J. M. Spurgeon, E. L. Warren, R. M. Briggs, N. S. Lewis and H. A. Atwater, Energy Environ. Sci., 2010, 3, 1037-1041.

12 S. W. Boettcher, E. L. Warren, M. C. Putnam, E. L. Santori, D. Turner-Evans, M. D. Kelzenberg, M. G. Walter, J. R. McKone, B. S. Brunschwig, H. A. Atwater and N. S. Lewis, J. Am. Chem. Soc., 2010, 133, 1216-1219.

13 S. Trasatti, in Advances in Electrochemical Science and Engineering, ed. H. Gerischer and C. Tobias, VCH, Weinheim, Germany, 1992 vol. 2 , ch. 1, pp. 1-85.

14 S. Trasatti, J. Electroanal. Chem., 1972, 39, 163-184.

15 M. Miles, J. Electroanal. Chem., 1975, 60, 89-96.

16 J. Divisek, H. Schmitz and J. Balej, J. Appl. Electrochem., 1989, 19, 519-530.

17 J. Jaksic, M. Vojnovic and N. Krstajic, Electrochim. Acta, 2000, 45, 4151-4158

18 I. Raj, J. Mater. Sci., 1993, 28, 4375-4382.

19 J. G. Highfield, E. Claude and K. Oguro, Electrochim. Acta, 1999, 44, 2805-2814.
20 Y. Tsuru, M. Nomura and F. Foulkes, J. Appl. Electrochem., 2002, 32, 629-634.

21 I. Lombardi, S. Marchionna, G. Zangari and S. Pizzini, Langmuir, 2007, 23, 12413-12420.

22 For the purposes of this report, the current density is the ratio of the current passed to the macroscopic (also called geometric or projected) area of the sample.

23 S. Trasatti and O. Petrii, J. Electroanal. Chem., 1992, 327, 353-376.

24 B. Conway, H. Angerstein-Kozlowska, M. Sattar and B. Tilak, J. Electrochem. Soc., 1983, 130, 1825-1836.

25 S. W. Boettcher, J. M. Spurgeon, M. C. Putnam, E. L. Warren, D. B. Turner-Evans, M. D. Kelzenberg, J. R. Maiolo, H. A. Atwater and N. S. Lewis, Science, 2010, 327, 185-187.

26 J. Stachurski, D. Pouli, J. Ripa and G. Pokrzyk, Low overvoltage hydrogen cathodes, U.S. Patent 4,354,915, 1982.

27 I. Raj and V. Venkatesan, Int. J. Hydrogen Energy, 1988, 13, 215-223.

28 C. Fan, D. Piron, A. Sleb and P. Paradis, J. Electrochem. Soc., 1994, 141, 382-387.

29 D.-L. Long, E. Burkholder and L. Cronin, Chem. Soc. Rev., 2007, 36, $105-121$.

30 A. Müller and C. Serain, Acc. Chem. Res., 2000, 33, 2-10.

31 E. Chassaing, K. Quang and R. Wiart, J. Appl. Electrochem., 1989, 19, 839-843.

32 M. de Chialvo and A. Chialvo, J. Electroanal. Chem., 1998, 448, 87-93.

33 J. O. M. Bockris, I. A. Ammar and A. K. M. S. Huq, J. Phys. Chem., 1957, 61, 879-886.

34 D. Brown, M. Mahmood, A. Turner, S. Hall and P. Fogarty, Int. J. Hydrogen Energy, 1982, 7, 405-410.

35 D. Brown, M. Mahmood, M. Man and A. Turner, Electrochim. Acta, 1984, 29, 1551-1556.

36 J. Freeouf, T. Jackson, S. Laux and J. Woodall, J. Vac. Sci. Technol, 1982, 21, 570-573.

37 R. C. Rossi and N. S. Lewis, J. Phys. Chem. B, 2001, 105, $12303-$ 12318.

38 M. D. Kelzenberg, S. W. Boettcher, J. A. Petykiewicz, D. B. TurnerEvans, M. C. Putnam, E. L. Warren, J. M. Spurgeon, R. M. Briggs, N. S. Lewis and H. A. Atwater, Nat. Mater., 2010, 9, 239-244. 